\title{
Soft skills and its impact on an organizational creativity-A field study
}

\author{
Abdallah Abdallah Ahmed El-Tabal \\ Department of Business Administration \\ Faculty of Commerce - Suez University, Egypt
}

\section{Keywords}

Soft skills, communication, teamwork, individual innovation, self-management, critical thinking, problem -solving, organizational creativity.

\begin{abstract}
The purpose of this study to investigate the relationship between soft skills and organizational creativity at the company Telecom Egypt in regions of Suez, South Sinai, and the Red Sea. To achieve research objectives, three basic hypotheses were formulated, and tested using primary data collected through the questionnaire, consisted of 251 questionnaires. Structural equation modelling and path analysis were performed to analyse the survey data and to test study hypotheses. The study found a strong positive relationship and significant effect of the soft skills dimensions of (communication, working in a team, individual innovation, self-management, critical thinking, problem-solving on organizational creativity, and the relative importance of the soft skills dimensions varies in their impact on organizational creativity, ranking as follow: critical thinking, self-management, problem -solving, communication, working in a team, individual innovation.
\end{abstract}

Corresponding author: Abdallah Abdallah Ahmed El-Tabal

Email addresses for the corresponding author: altabal2000@yahoo.com

First submission received: $23^{\text {rd }}$ April 2020

Revised submission received: $26^{\text {th }}$ May 2020

Accepted: $11^{\text {th }}$ June 2020

\section{Introduction}

Soft Skills consider one of the concepts that are frequently mentioned in recent years, refers to the basic skills that related to an individual's ability to interact with others, communicate with them, use leadership behaviours that characterize his relationships with others, initiative, and interact with clients, Working within a team, these skills also complementary to hard skills related to knowledge, experience, specialization, professionalism, and the ability to perform job tasks (Seth and Seth, 2013). Business owners emphasize the importance need for intangible, non-technical skills and these known as the skills of 21st the century, Includes of the individual and his interaction with others, shift in interest from manufacturing to interest in services, contribute to achieving a competitive advantage, and reducing unemployment, increasing employment (Quinley, 2013; Simpson, 2006).

Also called life skills, represent 75\% of worker skills (Rao, 2010), Gewertz (2007) called it also applied skills, The term soft skills receive great attention, acceptance, and popularity among writers and researchers in the field of business administration at present, because it considers important a key for achieving entrepreneurial organizations, and a critical factor for achieving economic and social progress (Tobin, 2008), Glenn ( 2008) sees it vital and imperative concept today and one of the most important priorities for high-performance organizations to maintain a competitive advantage.

The present study attempts to identify the relationship between soft skills and organizational creativity in the company Telecom Egypt regions (Suez, South Sinai, and the Red Sea). So, this study attempts to answer the following research question, what are the affect soft skills on organizational creativity? 


\section{Literature review}

\subsection{The concept of soft skills}

The results of study Seth and Seth(2013) indicate that $86 \%$ of employers agree on the importance of soft skills for success in the work environment, $60 \%$ of them see graduates in Work market do not have the skills needed to succeed in work, and $68 \%$ of them see that the ratio of soft skills to solid skills is $40: 40$ in favour of soft skills in public jobs, while the ratio is 50:50 in middle management jobs, and the ratio is 60:40 in favour of skills Soft in senior management positions, the results also indicate that The six most important soft skills from the employer`s point of view are arranged according to their importance to them : $99 \%$ for communication skill, $90 \%$ for personal skills, $6 \%$ for teamwork skill, $5 \%$ for leadership skill, $4 \%$ for conflict management skill, $2 \%$ for time management skill.

The study conducted by Hajjaj (2014) indicates that there is a Statistical significance relationship between job-hunting processes administrative and the soft skills dimensions (networking, strategic thinking, self-presentation, professionalism, crisis management, negotiation, anger management), report Mansour (2016) indicate there are important skills required to workers it is not available in Egypt include: basic skills such as: (communication- working in a team- problem solving), technical skills, management and leadership skills. While in Morocco the basic skills such as (communication, working in a teamproblem -solving- participation), management and leadership skills, Soft skills, and technical skills. And in Saudi Arabia it: management and Leadership skills, core skills such as (communication- team- work, problem-solving), marketing skills and technical skills. study Qwaider (2017) also indicate direct a statistical significant relationship between soft skills and improving the performance of workers in Palestinian ministries, and the performance is affected by the following soft skills dimensions (communication, teamwork, crisis management, decision making, planning, time management and work under pressure), Soft skills contribute to increasing productivity and efficiency in work, reducing work time and developing family life for workers.

Tang (2018) sees that soft skills are the cornerstone for achieving organizational success, as they necessary for organizations in the twenty-first century. The results of one study indicate that $75 \%$ of job success depends on dealing with others, while only 25\% depends on technical knowledge (Klaus, 2010), while the results of another study indicate that $85 \%$ of success in Work is due to soft skills, and Solid skills do not contribute For only 15\% success in an individual's work (John, 2009). Mahasneh's study (2016) addressed a theoretical framework for soft skills in building and construction sector using Six Sigma design, where employers in this sector face a large gap in soft skills, and the skills required in graduates are (Communication, thinking, conflict resolution, negotiation, teamwork, stress management, professionalism, productivity, work ethic, diversity, planning , organization, self-intelligence and social intelligence). Perera (2010) sees communication as soft skill consider the cornerstone to achieve success business and organization, Creativity is important problem-solving tool, Al-Farra (2016) believes that interest in developing the soft skills of workers is a means towards development, innovation, creativity and organizational renewal.

We conclude from the previous presentation the soft skills dimensions in this study include: (communication, working in a team, innovation, self-management, critical thinking, and problem solving) (see Figure 1). Therefore, in this study, it is hypothesized that:

H1: There is a statistically significant relationship between the soft skills dimensions and organizational creativity in the company Telecom Egypt.

\subsection{Organizational creativity}

Riyadh (2012) was measured organizational creativity in four dimensions (flexibility, originality, the spirit of risk, sensitivity to problems), the study found a strong and immediate correlation and effect between transformational leadership and organizational creativity. A study (Osama, 2014) indicates that there is a statistical significant relationship between organizational creativity and organizational and job performance, the elements of organizational creativity include: (originality, fluency, flexibility, risk, ability to analyse, sensitivity to problems and out of the ordinary). study (Koustab Ghosh, 2015) indicate that self-leadership behaviours, self-management, and self-motivation affect the level of individual and group creativity in the work environment, development of new ways to solve problems, critical and constructive 
thinking. A study Amrawi (2016) concluded that there is a statistically significant effect and the relationship between organizational creativity and competitive advantage in the small and medium companies, organizational creativity was measured in four dimensions (originality, fluency, sensitivity to problems, risk).

Al-Shammari and Al-Mabrik (2012) determine the organizational creativity dimensions as follow:

A. Fluency: An individual can generate a large number of ideas, alternatives and solutions and the focus is on the number of ideas and not on their type or quality.

B. Flexibility: The individual can generate diverse ideas or solutions that are not traditional ideas and solutions, the focus is on the diversity of ideas, not quantity.

C. Sensitivity to problems: The individual's ability to perceive weaknesses in a situation or problem by looking at the stimulus from different angles.

D. Risk Tolerance: The individual can accept risks and take responsibility and accept challenge and audacity.

We conclude from the previous presentation the organizational creativity dimensions in this study include: (the ability to fluency, sensitivity to problems, risk tolerance, acceptance of change).

\subsection{The relationship between soft skills and organizational creativity}

Alqurashi (2012) study indicate an impact of developing soft skills for workers on customer loyalty, where developing soft skills for workers contributes to Improving the quality of customer service, customer loyalty and improving employee's performance. study (Shabir, 2016) the results indicate a statistically significant relationship between soft skills (leadership, teamwork, communication, decision making, problem -solving, negotiation, planning and time management), student leadership trends (initiative, creativity, risk tolerance) and the soft skills variables affect the entrepreneurial orientation in order: (decision-making, problem-solving, negotiation, leadership, teamwork, planning, communication, time management). Aoun, Hasnan and Al-Aaraj (2018) the results of the study indicate that simplified practices significantly affect innovation skills of workers, while soft comprehensive quality management did not mediate this relationship due to its failure to implement it appropriately, especially at the level of management centered on human resources and continuous improvement in Lebanese hospitals.

We conclude from the previous presentation in this study it is hypothesized that:

$\mathrm{H} 2$ : There is a statistically significant effect relationship of the soft skills dimensions on the organizational creativity in Telecom Egypt.

This hypothesis is divided into the following sub- hypothesizes:

H 2-1: There is a statistically significant effect relationship between communication skill as one of the soft skills dimensions and organizational creativity in the company.

$\mathrm{H}$ 2-2: There is a statistically significant impact relationship between the skill of working in a team as one of the soft skills dimensions and organizational creativity in the company.

$\mathrm{H}$ 2-3: There is a statistically significant impact relationship between the skill of individual innovation as one of the soft skills dimensions and organizational creativity in the company.

$\mathrm{H} \mathrm{2-4:} \mathrm{There} \mathrm{is} \mathrm{a} \mathrm{statistically} \mathrm{significant} \mathrm{impact} \mathrm{relationship} \mathrm{between} \mathrm{the} \mathrm{skill} \mathrm{of} \mathrm{self-management} \mathrm{as} \mathrm{one} \mathrm{of}$ the soft skills dimensions and organizational creativity in the company.

H 2-5 There is a statistically significant effect relationship between the skill of critical thinking as one of the soft skills dimensions and organizational creativity in the company.

H 2-6 There is a statistically significant impact relationship between the problem-solving skill as one of the soft skills dimensions and organizational creativity in the company.

H3: The relative importance of soft skills dimensions varies in terms of influencing the level of organizational creativity.

\section{Research methodology}

\subsection{Methodology}

This research uses structural equation modelling (SEM) to measure the variables of the study. Based on the descriptive analytical approach is used in its survey method, which depends on data 
collection, organization, and analysis through relying on theoretical and field study method to achieve the objectives of the research. Figure 1 illustrates The Proposed research framework.

Figure (1) the proposed model for the study

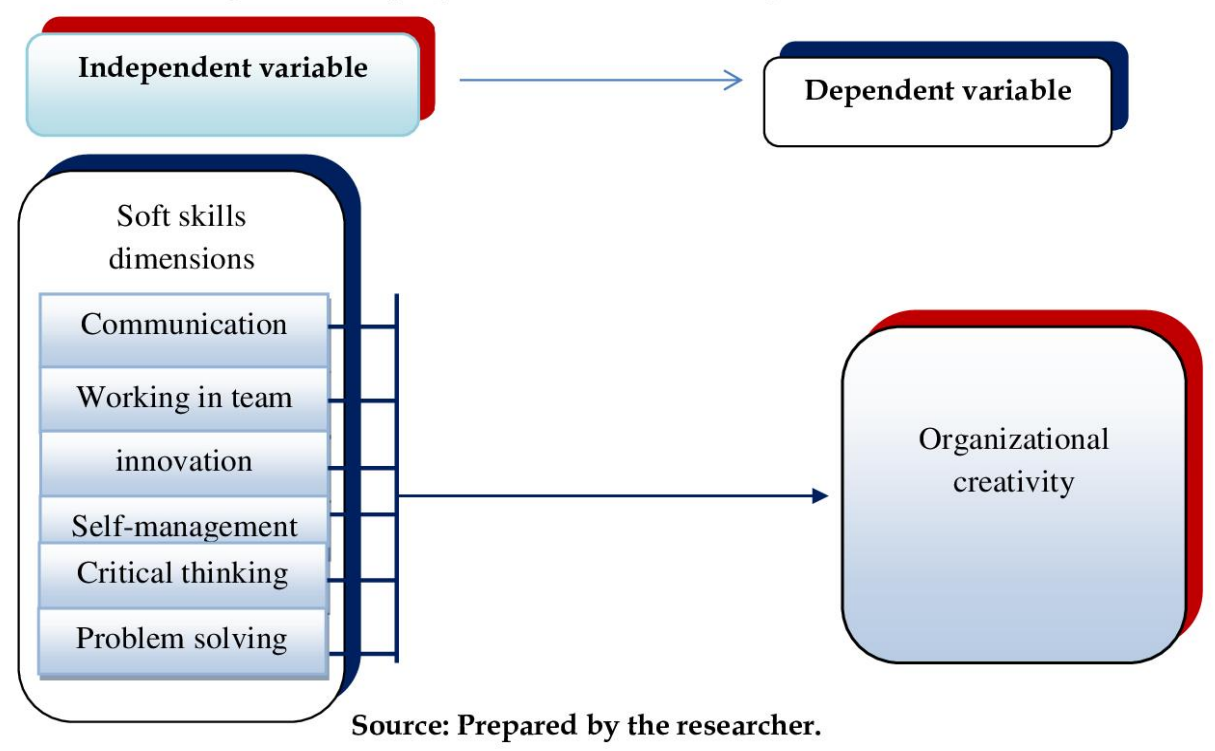

\subsubsection{Measuring variables}

First, a measurement model is designed to determine the significance of path coefficients (factor loadings) between multiple variables (observed variables) and (latent variables), it allows making sure the validity of the model. Next, a structural model is designed to verify the significance of statistical influences or regression weights, enabling testing of the causal relationships between the variables that were hypothesized in the proposed conceptual model.

\subsubsection{The questionnaire design and data collection}

A Questionnaire was designed to measure the soft skills dimensions in this study (independent variables), and based on the scale of (Hajjaj, 2014), (Qwaider, 2017). As for the dimensions of the dependent variable, organizational creativity was measured based on the scale of (Jawwal, 2015), (AlHarahsheh and Al-Haiti, 2006), (Al-Zoubi, 2013), (Amrawi, 2016), with some required adjustments to the phrases to suit the objectives of the current study, As well as an open question about the proposals of the research groups regarding the contribution of soft skills in developing the level of organizational creativity. And a set of questions related to general data to know the characteristics of the research sample. The five-point Likert scale was used. The questionnaire was used to collect data, is divided into three parts, the first part: demographic data (age, gender, level of education). The second part deals with information about the soft skills dimensions under study (independent variables): (communication, working in a team, innovation, self-management, critical thinking, problem- solving), the third part deals with information about the organizational creativity dimensions (dependent variable): (the ability to fluency, sensitivity to problems, risk tolerance, acceptance of change).

\subsubsection{Research population and Sampling}

The research population is represented in the Egyptian Telecom Company, the sectors of the regions (Suez, South Sinai and the Red Sea), and it is clear the heterogeneity of the vocabulary of the research population, and a stratified random sample was pulled out of its total size according to the sample size tables (274) single, the size of population (939) single during February 2019 (Sekaran, 2003). The number of valid lists reached 251 lists, and the rate of correct responses reached \%91.6, which is a high and acceptable rate for scientific research purposes. 


\section{Data analysis}

\subsection{Measurement model}

The researcher used The Social Sciences Statistical Package (SPSS / PC +, v. 22), (AMOS, v. 22), Use the SEM model equations to test the suitability or conformity of the model to the data. The following statistical methods due to their compatibility with the nature of the study data:

The Alpha Cronbach's Reliability Coefficient to assess the reliability of the set of phrases that measure study variables, the Confirmatory Factor Analysis (CFA) to verify structural validity of the scale, exploratory factor analysis (EFA) to test the validity and veracity of study variables, Composite Reliability (CR), and Average Variance Extracted (AVE), (see table 1). Path analysis and determination of Critical Ratio for Regression Weight to test the hypotheses of the study and verify the existence of a significant relationship between the dimensions of the independent and dependent variable.

Table (1) exploratory factor analysis, Confirmed Factor Analysis, Composite Reliability, Cronbach's Alpha Average Variance Extracted

\begin{tabular}{|c|c|c|c|c|c|}
\hline Items & EFA & CFA & $\mathrm{R}$ & Cronbach's alpha & VE \\
\hline com1 & .82 & .75 & & & \\
\hline $\operatorname{com} 2$ & .80 & .74 & & & \\
\hline $\operatorname{com} 3$ & .83 & .80 & & & \\
\hline com 4 & .90 & .92 & & & \\
\hline communication & & & 86 & .85 & 68 \\
\hline Team1 & .90 & .87 & & & \\
\hline Team2 & .90 & .88 & & & \\
\hline Team3 & .91 & .88 & & & \\
\hline Team4 & .88 & .83 & & & \\
\hline Team & & & 92 & .92 & 76 \\
\hline Innov1 & .85 & .84 & & & \\
\hline Innov2 & .86 & .83 & & & \\
\hline Innov3 & .84 & .82 & & & \\
\hline Innov4 & .84 & .80 & & & \\
\hline Innovation & & & 7. & .86 & 71 \\
\hline Self1 & .80 & .76 & & & \\
\hline Self-2 & .81 & .88 & & & \\
\hline Self-3 & .76 & .70 & & & \\
\hline self-management & & & 8 & .89 & 68 \\
\hline Criti1 & .90 & .90 & & & \\
\hline Criti2 & .91 & .88 & & & \\
\hline Criti3 & .87 & .85 & & & \\
\hline Criti4 & .88 & .89 & & & \\
\hline critical thinking & & & 91 & .90 & 80 \\
\hline Prob1 & .80 & .78 & & & \\
\hline Prob2 & .81 & .78 & & & \\
\hline Prob3 & .79 & .76 & & & \\
\hline Prob4 & .78 & .73 & & & \\
\hline Problem- solving & & & 92 & .91 & 75 \\
\hline Org1 & .86 & .69 & & & \\
\hline Org2 & .84 & .68 & & & \\
\hline Org3 & .87 & .73 & & & \\
\hline Org4 & .94 & .86 & & & \\
\hline $\begin{array}{l}\text { organizational } \\
\text { creativity }\end{array}$ & & & 0 . & .79 & 61 \\
\hline
\end{tabular}

It is clear from the previous table that the values of the alpha coefficient range between $(79 \%, 92 \%)$, the values of confirmatory factor analysis are between $(68 \%, 92 \%)$, Composite Reliability values are between $(80 \%, 92 \%)$, and the values of the Average Variance Extracted Between $(61 \%, 80 \%)$, exploratory 
factor Analysis between $(76 \%, 94 \%)$, This means an acceptable increase in the reliability of each variable, where all values exceed $50 \%$ and the height of the dependency coefficients reflects the high degree of internal consistency and honesty between the contents of each of the previous variables, and also means the ability to rely on these variables in practice, and the validity of the model to measure variables studying. The survey is accepted if the Alpha Cronbach's coefficient or persistence ratio is greater than 60\% (Sekaran, 2003; Mcclave, Benson and Sincich, 2001).

\section{Testing of hypotheses}

Figure (2) path analysis of the proposed structural equations model for the study variables

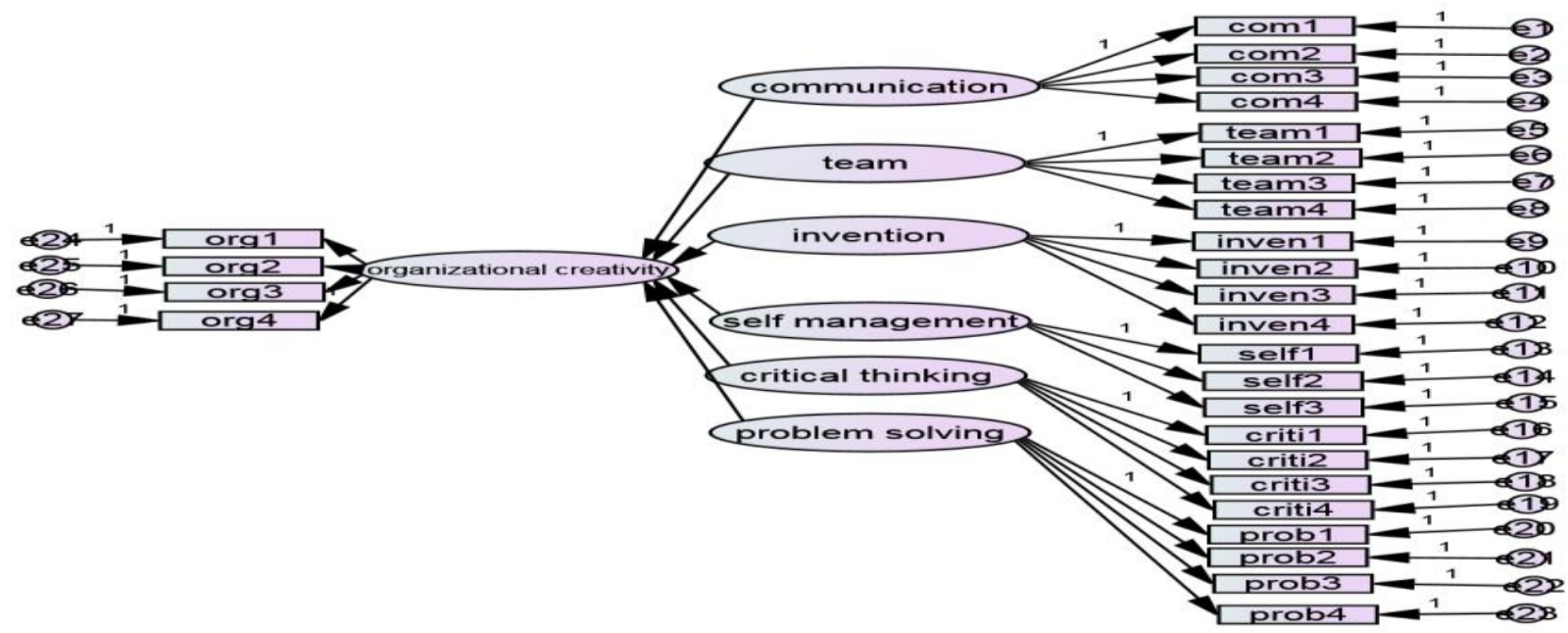

The following table shows indicators of conformity or suitability for the proposed structural model for the study:

Table (2) Conformity quality indicators for the proposed SEM structural model for the study (model fit)

\begin{tabular}{|l|l|l|}
\hline Measures & Fit Indices & Threshold Values \\
\hline CMIN/DF & 2.1 & Less than 3 \\
\hline GFI & 0.98 & 0.90 and above \\
\hline AGFI & 0.97 & 0.90 and above \\
\hline CFI & 0.96 & 0.90 and above \\
\hline TLI & 0.98 & 0.90 and above \\
\hline NFI & 0.97 & 0.90 and above \\
\hline RMSEA & 0.05 & Less than 0.08 \\
\hline
\end{tabular}

It is clear from the previous table that all the values of indicators of conformity or suitability of the model are high and exceed the ideal limits, which means acceptance and validity of the model to measure the relationship between the study variables. To test the study hypotheses and verify that there is a significant relationship between the dimensions of the dependent and independent variable, the following table displays a summary of the results of the regression coefficients between the study variables:

Table (3) Regression Weights: (Group number 1 - Default model)

\begin{tabular}{|lll|lllll|}
\hline & & & Estimate & S.E. & C.R. & P & abel \\
\hline communication & $<---$ & organizational creativity & 1.718 & .532 & 3.230 & .001 & \\
team & $<---$ & organizational creativity & .432 & .198 & 2.181 & .029 \\
innovation & $<---$ & organizational creativity & .105 & .051 & 2.070 & .038 \\
self-management & $<---$ & organizational creativity & .330 & .092 & 3.596 & $* * *$ & \\
critical thinking & $<---$ & organizational creativity & 1.240 & .337 & 3.676 & $* * *$ & \\
problem solving & $<---$ & organizational creativity & 1.394 & .407 & 3.429 & $* * *$ & \\
\hline
\end{tabular}

It is clear from the previous table that the proposed model of the study included good values for indicators, and this is shown by the table of indicators of conformity quality, and all estimates of the 
model are significant at the level of significance 0.05 . The calculated value is greater than the tabular value of $C R \pm 1.96$, and values this indicates that the expressions for each dimension are able to measure and accept the values of the structural validity coefficients for the scale, and therefore can be relied upon to estimate the relationship between the independent variable and the dependent variable.

Through the results shown in the previous table, the following hypothesis can be tested as follow:

The hypothesis (H1) was accepted, as all model estimates were significant at 0.05 level of significance, and calculated CR values were greater than the tabular value of \pm 1.96 , indicating that this relationship was significant.

The hypothesis $(\mathrm{H} 2 / 1)$ was accepted, a value of $\mathrm{CR}=2.230$ (i.e. more than \pm 1 . 96) that indicate to the effect of an independent variable on the dependent variable is significant, and (Estimate $=1.718$ ) with a positive sign indicating that there is a positive relationship between communication skill and organizational creativity, and significant, the value of $\mathrm{P}=.001$ (i.e. less than 0.05 ) This indicates the relationship is significant.

The hypothesis $(\mathrm{H} 2 / 2)$ was accepted, a value of $\mathrm{CR}=2.181$ (i.e. more than \pm 1 . 96) that indicate to the effect of an independent variable on the dependent variable is significant, and (Estimate $=0.432$ ) with a positive sign indicating that there is a positive relationship between skill of working in team and organizational creativity, and significant, the value of $P=.029$ (i.e. less than 0.05) This indicates the relationship is significant.

The hypothesis $(\mathrm{H} 2 / 3)$ was accepted, a value of $\mathrm{CR}=2.070$ (i.e. more than \pm 1 . 96) that indicate to the effect of an independent variable on the dependent variable is significant, and (Estimate $=0.105$ ) with a positive sign indicating that there is a positive relationship between skill of individual creativity and organizational creativity, and significant, the value of $P=.038$ (i.e. less than 0.05 ) This indicates the relationship is significant.

The hypothesis $(\mathrm{H} 2 / 4)$ was accepted, a value of $\mathrm{CR}=3.596$ (i.e. more than \pm 1 . 96) that indicate to the effect of an independent variable on the dependent variable is significant, and (Estimate $=0.330$ ) with a positive sign indicating that there is a positive relationship between skill of self-management and organizational creativity, and significant, the value of $P=.000$ (i.e. less than 0.05 ) This indicates the relationship is significant.

The hypothesis $(\mathrm{H} 2 / 5)$ was accepted, a value of $\mathrm{CR}=3.676$ (i.e. more than \pm 1 . 96) that indicate to the effect of an independent variable on the dependent variable is significant, and (Estimate $=1.240$ ) with a positive sign indicating that there is a positive relationship between skill of critical thinking and organizational creativity, and significant, the value of $P=.000$ (i.e. less than 0.05 ) This indicates the relationship is significant.

The hypothesis $(\mathrm{H} 2 / 6)$ was accepted, a value of $\mathrm{CR}=3.429$ (i.e. more than \pm 1.96$)$ that indicate to the effect of an independent variable on the dependent variable is significant, and (Estimate $=1.394$ ) with a positive sign indicating that there is a positive relationship between problem-solving skill and organizational creativity, and significant, the value of $P=.000$ (i.e. less than 0.05 ) This indicates the relationship is significant.

The most influential dimensions in organizational creativity are critical thinking, then selfmanagement, then problem solving, followed by communication, then teamwork and finally individual innovation.

As a result of proving the validity of the hypotheses, the main hypothesis is validated, which states that there is a significant influence relationship between the soft skills dimensions and organizational creativity. Thus, the second main hypothesis $\mathrm{H} 2$ is fulfilled, there is a statistically significant effect relationship of the soft skills dimensions on the organizational creativity.

The hypothesis H3: was accepted, it is clear from the proof of the second hypothesis that the most influential dimensions in organizational creativity are: critical thinking, followed by self-management, then problem solving, then communication, followed by teamwork and finally individual creativity. Thus, the order of the independent variables in terms of their effect on the dependent variable is as follow: (Critical thinking, Self-management, Problem-solving, Communication, Teamwork, Individual creativity). Then accept the third hypothesis. 


\section{Discussions}

The topic of creativity is one of the most dynamic and soft topics, and the need for it increases and it occupies great importance in previous researches and studies at present, as it plays an important role in the development of organizations, success, survival, a competitive and global environment characterized by speed and complexity, consider a competitive advantage. So, this research contributes to the exploration of the factors that affect organizational creativity.

This study has found that there is a positive relationship between soft skills dimensions and organizational creativity. The main contribution of the research is soft skills effect on organizational creativity, the relationship between soft skills and organizational creativity need to increase organizational creativity by the ability to fluency, sensitivity to problems, risk tolerance and acceptance of the change. The other contribution is that the study found that there is a statistically significant relationship between the soft skills dimensions and organizational creativity. The results of this study are consistent with the results of previous studies in this field, such as the study of Shabir (2016) indicates a statistically significant relationship between soft skills and (initiative, creativity, risk tolerance), and Al-Farra (2016) interest to developing the soft skills of workers as means towards development, innovation, creativity and organizational renewal. Another contribution is that the study found that there is the order of the independent variables or the soft skills dimensions in terms of their effect on the dependent variable or the organizational creativity is as follow: (Critical thinking - Self-management - Problem solving Communication - Teamwork - Individual creativity), This result is consistent with the results of the study of Shabir (2016). Thus, the three research hypotheses are validated.

\section{Conclusion}

This study provides additional evidence to the literature concerning the impact of soft skills dimensions on the organizational creativity, This study contributes by highlighting some factors that have not been widely examined in literature such as (Critical thinking, Self-management, Problem-solving, Communication, Teamwork, Individual innovation), Although this study has proved that soft skills dimensions effect on increased organizational creativity. Aoun, et al. (2018) highlights that the relationship between simplified practices, soft comprehensive quality management, and innovation skills, results indicate that simplified practices significantly affect innovation skills, Alqurashi (2012) results of study indicate an impact of developing soft skills for workers on customer loyalty, where developing soft skills for workers contributes to Improving the quality of customer service and customer loyalty and improving employee performance, and soft skills are now considered a way for organizations to retain customers and gain customer loyalty, Shabir (2016) results indicate a statistically significant relationship between soft skills and student leadership trends (initiative, creativity, risk tolerance), Al-Farra (2016) believed that interest in developing the soft skills of workers is a means towards innovation, creativity development and organizational renewal.

\section{Managerial implications}

According to the results of this research, it is clear that in the Telecom Egypt, the regions sector (Suez, South Sinai and the Red Sea), management attention should be given to the concept of soft skills, which is one of the modern topics, especially with the increase in unemployment rates and the employment crisis among graduates at the present time and relationship between soft skills and organizational creativity.

This study contributes to increasing the understanding of managers the need of term soft skills and managers are advised to focus on providing this skills to increase organizational creativity, where competition and sustainability in the business world today are based on skills, knowledge and information. soft skills they affect the behaviour of employees and improve their performance and harmony with others, and employers agree that soft skills are a critical and important factor for achieving success in the work environment, and is an investment in the long term, and it is one of the research priorities at the present time.

We suggest some recommendations that enable the management of the company identifying the best soft skills and their role in developing organizational creativity such as focusing on preparing workers who possess self-management enabling them to integrate into the work environment with 
flexibility, ability to learn for life, and must be included soft skills in teaching, learning and evaluation processes, training, and focus on the practical side more than the theoretical side, Supporting innovation and investment in technical education for lifelong learning based on technology, prepare training programs for workers in the company in the field of soft skills to improve job performance and to achieve the highest levels of quality.

\section{Limitations and Trends of Future Research}

The model of the study was tested in Telecom Egypt, the region`s sector (Suez, South Sinai, and the Red Sea). This study has found that a strong positive relationship and a statistically significant effect of the dimensions of the soft skills: (communication, Working in a team, individual innovation, selfmanagement, critical thinking, problem- solving) in the level of organizational creativity, and it varies the relative importance of the soft skills dimensions in this study in their impact on organizational creativity, as following (critical thinking - self-management, problem-solving, communication, working in a team, individual innovation).

The researcher recommends conducting more studies in the field of soft skills dealing with the following issues: Study, analyse and measure ROI in soft skills, the role of creative leadership in building soft skills, measuring the impact of soft skills on financial performance, and improving the organizational performance.

\section{References}

Al-Farra ,M. M. I., (2016), Proposed Training Program for Soft Skills Development in the Light of the United Nations Declaration on Education for Sustainable Development and the Sustainable Development Strategy Egypt 2030, The Fourteenth Annual Conference: From Adult Education to Lifelong Learning for All for Sustainable Development, Adult Education Center Ain Shams University.

Al-Harahsheh, M., and Al-Haiti, S., (2006), The Impact of Administrative Empowerment and Organizational Support on Creative Behavior as Seen by Jordan Telecom Company: A Field Study." Journal of Administrative Sciences Studies, University of Jordan, Volume 33, No. 2, pp. 240-265.

Al-Shammari, A. B. A., and Al-Mabrik, W. B. N., (2012), Entrepreneurship, Riyadh.

Alqurashi, N., (2012), Critical analysis of the Impact of employee development by focusing on soft skills on customer loyalty, Manchester metropolitan university, school of Business, Biritsh, pp.1-62.

Al-Zoubi, M.,(2013 ), The Impact of the Organizational Climate on the Creative Behavior of Workers: A Case Study on the Jordanian Orange Telecom Company in the City of Irbid ", Journal of Administrative Sciences Studies, University of Jordan, Volume 21, No. 1, pp. 122-192.

Amrawi ,M., (2016), the effect of organizational creativity on achieving competitive advantage in small and medium enterprises, case study of a sample of small and medium enterprises, mills sector in the wilayats of Ouargla and Taftar, a note submitted to complete the requirements of an academic master's degree, the Faculty of Economic Sciences, Commercial Sciences and Management Sciences, the University of Kassadi Murbah, Ouargla, Algeria, pp. 1-45.

Aoun, M., Hasnan, N. and Al-Aaraj, H., (2018), Relationship between lean practices, soft total quality management and innovation skills in Lebanese hospitals, EMHJ, Vol. 24 No. 3, pp.269-276.

Gewertz, C., (2007), Soft skills in big demand: Interest in teaching students' habits of mind for success in life is on the rise. Education Week, 26(40), June 12, PP. 25-2.

Glenn, L., (2008), The "new" customer service model: Customer advocate, company ambassador, Business Education Forum, April,62(4), PP. 7-13.

Hajjaj ,A.N. O., ( 2014 ), The role of soft skills in the process of snatching administrative jobs - an applied study on administrative jobs in the Gaza Strip, master's thesis, Islamic University of Gaza, Deanship of Graduate Studies, College of Commerce, Department of Business Administration .

Jawal, M.A., (2015), "Empowerment and its impact on developing creative behavior in the economic institution: a field study", PhD thesis, College of Economic, Commercial and Management Sciences, Hassiba Ben Bouali University, Chlef, Algeria.

John, J., (2009), Study on the nature of impact of soft skills training programme on the soft skills development of management students Pacific Business Review, October/December 19-27. PP 5-1.

Klaus, p., (2010), Communication breakdown. California Job Journal, 28, pp.1-9.

Koustab, G., (2015),"Developing organizational creativity and innovation: Toward a model of selfleadership, employee creativity, creativity climate and workplace Innovative orientation orientation", Management Research Review, Vol.38Issue: 11, pp.1126-1148. 
Mahasneh ,J. K.,( 2016) ,A Theoretical Framework for Implementing Soft Skills in Construction Education Utilizing Design for Six Sigma, Dissertation submitted to the faculty of the Virginia Polytechnic Institute and State University in partial fulfilment of the requirements for the degree of Doctor of Philosophy Environmental Design and Planning, April 28th .

Mansour ,S., (2016 ), abstract of a research paper on the Cultural Skills Unit, an in-depth look at the gaps and shortcomings in cultural skills in: Egypt, Morocco and Saudi Arabia, the Cultural Skills Unit at the British Council, pp. 1-16.

Mcclave, J.T., Benson, P.G., and Sincich, T.L., (2001), Statistics for Business and Economics, Eight, ed., Prentice Hall, Inc., Canada.

Osama ,A. M., ( 2014 ), the impact of organizational creativity on the performance of workers in small and medium enterprises, the case of the Plastic Conversion Unit Company in South Ouargla, a draft memorandum submitted to complete the requirements for an academic master's degree, Kassadi University Murbah and Ouargla, Faculty of Economic Sciences, Commercial Sciences and Traffic Sciences, Algeria, pp. 1-39.

Perera, B.M.K., (2010), Important Skills applicable to the World of work: A Guide to Soft Skills, University of Peradeniya, February.

Rao, M. S., (2010), Which are The Employability: www.career-journal.com.

Riyadh, A. R., (2012), The Role of Transformational Leadership in Achieving Organizational Innovation, Case Study: The European Foundation for Spinning and Fatwa in Ein Jasser-Batna, a memorandum submitted as part of the requirements for obtaining a master's degree in management sciences, branch of organizations management, specialization in human resources, faculty of economic, commercial and traveling sciences, Algeria, Dar Al-Manzuma, Egyptian Knowledge Bank.

Sekaran, U., (2003), Research methods for business: A skill building approach, (4th ed.). India: John Wiley \& Sons Inc.

Seth, D., and Seth, M., (2013), IUP, Journal of Soft Skills., Vol. 7 Issue 1, PP 7-2.

Shbair, S. R., (2016), Soft skills and their relationship to entrepreneurial orientations among students of technical and vocational colleges in the governorates of Gaza, Master Thesis, Islamic University of Gaza, Faculty of Commerce, Palestine.

Simpson, S. J. A., and Simon. J. A., (2006), The Measurement and Recognition of Soft Skills Developing A Common Standard. www.Pdf sebook.com.

Tang, K. N., (2018), The importance of soft skills acquisition by teachers in higher education institutions Kasetsart, Journal of Social Sciences xxx, PP. 1-6.

Tobin, P.,( 2008), Soft Skills: The Hard Fact: www.prowess.org.Uk .

Qwaider, A. M. R., ( 2017), The role of soft skills in improving the performance of workers in the Palestinian ministries, Master Thesis, Joint Graduate Program between the Academy of Administration and Politics for Graduate Studies and Al-Aqsa University in Gaza, Palestine. 